\title{
Challenges Faced by Teachers and Learners on Drug and Substance Abuse in Public Secondary Schools in Kenya
}

\author{
Richard Rono, Isaac Njuguna Kimengi and Felicity W Githinji* \\ Department of Educational Foundations, Moi University, P.O. Box 3900-30100, Eldoret, Kenya
}

DOI: $10.36348 /$ SJHSS.2019.v04i10.002 $\quad$ | Received: 02.10.2019| Accepted: 09.10.2019| Published: 27.10 .2019

*Corresponding author: Dr. Felicity Wanjiru Githinji

\section{Abstract}

Drug and alcohol are significant problems that affect school-age adolescence at earlier age than in the past. Young people frequently start to experiment alcohol, tobacco, and other drugs during the middle school years, with a smaller number beginning during middle school years, and a smaller number starting during high school. The purpose of this study was to look into challenges faced by teachers and learners on drug and substance abuse in selected public secondary schools in Kenya. The research was based on social learning theory. The research was conducted in Nandi County schools in Kenya. Twenty four randomly selected schools out of 235 county schools were engaged in the study. A sample size of 1292 respondents was obtained using purposive and simple random sampling techniques. The participants included Deputy Principals, Counselors, and teachers teaching Life Skills subject, students and Focus Discussions Groups. Questionnaires and structured interviews were used to collect the data. The data collected was analyzed using descriptive statistics, frequency tables and percentages. The findings of this study revealed that more than half (65\%) of all respondents pointed out that there was poor implementation of drug abuse policies that hinder drug abuse decline among students in public secondary schools. More than half $(54 \%)$ indicated that family challenges were pressing and most critical hindrances towards decline of drug abuse among secondary schools. Majority (85\%) of the respondents, Deputy Principals, Life Skills teacher and Counselors, Focus Discussion Group reported that frustrations have made students to abuse drugs. Most respondents (85\%) of the four major groups combined, Deputy Principals, Life Skill Teachers, Counselors, Focus Discussion Groups pointed out day school students was one of the critical challenge in drug abuse reduction among students in public schools. Outsiders were found to be clandestinely selling drugs to students during festivities such as music and games. Teachers and school security officers in most schools did not bother to check on student luggage on arrival during opening and midterms which became an easy leeway of getting drugs into schools. The study recommended that drug abuse in schools was a challenge that needed to be addressed by all stake holders in education. Guidance and counseling in schools should be revamped, intensified and adequately inspired to cater for the needs of all students including those affected by drugs

Keywords: Challenges, teachers, learners, social net-working, Drugs and Substance Abuse.

Copyright @ 2019: This is an open-access article distributed under the terms of the Creative Commons Attribution license which permits unrestricted use, distribution, and reproduction in any medium for non-commercial use (NonCommercial, or CC-BY-NC) provided the original author and source are credited.

\section{INTRODUCTION}

Drug and alcohol are significant problems that affect school-age adolescence at earlier ages than in the past. Young people frequently start to experiment alcohol, tobacco, and other drugs during the middle school years, with a smaller number starting during the middle school years, with a smaller number starting during high school. By the time adolescents' are in high school, rates of drug use are remarkably up. According to data from the national survey, a third of twelfth graders reports being drunk or binge drinking in the most recent month; furthermore, nearly half of secondary school students report ever using marijuana and more than a quarter reported using marijuana in the past month in the U.S. [1].

Adolescence is the period in life when most drug use begins. According to [2], young people consume drugs for a host of reasons and under a number different circumstances and conditions. Drug use during adolescence is a social phenomenon that in most cases emerges as group experience with peers. It is viewed by the majority of young people as a way of maturing and abandoning childhood and parental control in pursuit of happiness. They further observe that where happiness flops, developmental problems emerge and this can drive the youth to abuse drugs. 
Elsewhere, The Kenya Pharmacy and poisonous Board have cited lifestyle and prescription drugs such as antibiotics and anti-malarial drugs as some of the most abused drugs by young people in Kenya. Some patients, instead of taking the right dosage of anti-malarial, insist on one pill or injection and in most cases, quacks give in to their demands resulting in outright abuse of drugs and substances.

According to [3] drug dynamics commences as early as ten or eleven years with the experimental use of inhalants such as glue petrol, eraser fluid, and aerosols. To them, drinking quite often begins at the age of twelve and use of dagga almost takes place at the same time. As [4] observes that this is the stage when children get acquainted with alcohol, tobacco, and other related drugs and develop a curiosity to find out how they taste and work. Children's friends are always the first to introduce them to these substances.

\section{Experimentation Is an Easier and Freer Way of Submitting To Pressure}

According to [5] societal pressure from friends and media is a common risk factor for substance and drug abuse among under-age students in both developing and developed countries. The phenomenon is largely common in towns and cities where there is a rampant interaction to advertising on television, radio and colorful billboards. Adolescents dwelling in a metropolitan environment are constantly prone to pictures and messages promoting a variety of alcohol brands and cigarettes than their counterparts in the countryside. It is argued and believed that the media plays a larger role in first-time cigarette use. Hon. Ngilu, former Kenyan Health Minister, said in 2006 that when youngsters watch their "heroes" smoking on television and cinemas, they are tempted to copy them without the full knowledge of the negative consequences of cigarettes power. Further, a report conducted by Ministries of Health and Education, in 2016, supported by WHO manifested that up to $80 \%$ of adolescents have seen messages promoting use of cigarettes in magazines and newspapers, and that $50 \%$ of cigarette users, and $20 \%$ of the new smokers, objects such as pens, caps and T-shirts with cigarette symbols. The report further stated that $25 \%$ of tobacco users thought that girls and boys who smoked looked more attractive and sailed in high prestige. This, impacts negatively on students since they associate smoking with being "cool" guys of the moment.

Most of the young people get hooked to drugs during social engagements such as open parties where people socialize freely and drinks like alcohol are available for free and young people are encouraged to take or tempted to try the staff. As well narcotics such bhang and cigarettes are equally availed for parties to be complete. Since alcohol is part of the enjoyment, it attracts the youth who want to identify and be equal members of the peer group entertainment. Open parties become forums of social networking for the youth where they introduce to drug abuse which gradually will lead drug abuse.

Nightclubs are also social joints where underage children are introduced and hooked to drugs. The nightclubs usually operate at night and last to the wee hours of the following morning. It is on such premises that dagga smokers are present and they supply the product for consumption on request with no discrimination so long as one meets the cost regardless of age. It is business time. As part of the interaction, the dealers may offer the staff for to those who are interested at first. But as the young people develop interest and get hooked, the dealers begin to charge. In the long run, many a young are made slaves of drug abuse without prior knowledge of where they were heading to. They only find themselves in a sea of problems where there is no turning back!

Well-off families very often host parties in homes their where all sorts of drinks are availed for merrymaking and everyone who is in the home is not restricted in what he or she is interested in taking. This becomes a starting point for the young people to experiment with drugs. If the parents are strict on alcohol and other drug intakes among the young people, they usually work out their way and out-smart their parents. They bring alcohol without the knowledge of their parents during parties and hide it in the garden. Dagga as well is smoked in the garden. Parents are taken by surprise when they suddenly observe a change in the behavior of their children during the party.

NACADA [6] observed that there was a strong connection between drug abuse and alcohol by the youth and disappearance of family values. In traditional African communities, open drunkenness was frowned upon. But presently, binge drinking is the order of the day. Parents drink before their children and some even allow their own to take alcohol in their presence as part of family entertainment. The report further says children as young as ten years are heavy drinkers of alcohol to the extent that some have ended up in rehabilitation centers. Such incidence clearly reflects serious problems that are the outcome product of how adolescents are socialized, in relation to drug and alcohol abuse.

According to Daily Nation [7], in some Nairobi High schools, students working in collaboration with school security officers, janitors and school cooks were clandestinely transacting drugs in the school among other students. It was also discovered that local transport touts and drivers were making a kill by selling illicit drugs to students in bus stages. Students responded that the drug deals were carried out secretly and only the trusted clients obtained the commodity. The students affected most are those inform one and form two classes. 
Drugs, alcohol and substance abuse among high school students are a universal challenge and no nation is spared from this phenomenon. It is not easy to quantify the actual scope and nature of drug and substance abuse among students, but most studies carried out points out that majority of the adolescent's tryout alcohol or any other drug while at their institution. It is approximated that roughly $25 \%$ of male and $10 \%$ of female teens abuse drugs on an average of once a week [8].

The Nigerian National Drug Law Enforcement Agency [9], states that drug abuse is a real monster in schools. For instance, twenty percent of students in Lagos state had consumed psychoactive drugs at least once in their lives. The main problem is that most of these behaviors are heavily tied to the peer culture, as children learn and imitate the age-mates they like and admire. The youth usually aspire to be attractive and important before their peers and this move is significant in the development of alcohol intake, tobacco, and other drug use as well as not practicing safe sex among other unwelcome behavior. Research has found out that adolescents that indulge in these risk behaviors are in most cases in constant conflict with school authorities, parents and suffer from poor self- control.

After school sessions are high-risk moments for alcohol and illegal drug use, unprotected sex and violence among young people. From research findings, approximately one-third of all violent juvenile crimes take place between the hours of three p.m. and seven p.m., when many children are on their own. Targeted programs at this crucial time can prevent, reduce or delay the genesis of alcohol, tobacco, and other drug consumption. After-school programs can reinforce social skills learned in the school and at home [10].

Kenyan secondary schools are being threatened by the drug and substance menace. The challenge is usually handled by the school authorities and when it stretches to an extreme, it is left to the police and is regarded as a criminal offense. The students who abuse drugs hide this fact for fear of retribution and getting jailed. Studies on drug prevention program in schools are worrying considering the meager knowledge is given to teachers on DSA which does not allow them to cater for specialized intervention. In this respect, therefore, there is a need for urgency to develop specialized DSA intervention program in Kenyan public secondary schools since it has become quite apparent that negative social influence is the main factors contributing to young people's genesis to using drugs and substances [11].

Global Tobacco Youth Survey-Kenya [12] observes that about $13 \%$ of all children in Kenyan schools smoke cigarettes and some begin as early as seven years. The report further states that $30 \%$ of school-going children are vulnerable to cigarette smoke in their homes. As well, a research carried out by two sister ministries of Education and Health with the help of World Health Organization (WHO) manifest that up to $80 \%$ of students in school had come across adverts encouraging the use of cigarettes in magazines, newspapers and billboards among others. The report further indicates that $50 \%$ of cigarette users and $20 \%$ of the incoming smokers had objects in form of pens, $\mathrm{T}$ shirts and caps with cigarette signs. The study also shows that $25 \%$ of student cigarette users took it that school students that smoke were attractive and smart. This socio-scenario exhibits that marketing connects cigarette use with being a cool and gentle person who needs to be emulated. This obviously places a good number of students at risk of getting entangled in drug and substance abuse.

According to the latest nationwide study done by Rapid Assessment on Drug and Substance [13], drug and substance abuse in Kenya has reached the agonizing stage. It was found that one in three adolescents has reported using one or more than one drug. The study indicates that alcohol use was the most frequently abused drug with $36.3 \%$ of the school children indicating a lifetime use. Khat or Miraa came second as $35.5 \%$ of students consume it, cigarettes $20.2 \%$, bhang $9.8 \%$, kuber $5.5 \%$, followed by heroin $3.1 \%$, inhalants $2.7 \%$, mandrax $2.6 \%$ and lastly cocaine $2.2 \%$. This trend, therefore calls for concerted effort to dig deeper into the matter and identify ways and means (social networks) that students use to introduce harmful drugs to schools and develop intervention measures to be put in place to save the youth from the ravaging threat of DSA in Kenyan secondary schools. The report further states that the root cause of these behaviors is mainly the parents who have progressively embraced a laissez-faire parenting system where they think their school going children are mature enough to make the right life choices and decisions independently.

Other reasons for taking drugs among high school students in the U.S include low esteem, need to experiment with drugs, constant exposure to chemical society of pills and liquor through advertisements, movies, and television [14]. At times need for simple pleasure drives students to go for DSA. According to U.S. Department of Education [15], drugs and substances produce a number of effects including memory distortion, perceptions, and sensation, for instance, cocaine and amphetamines give consumers a false feeling of performing at a high level having taken the drug. 


\section{OBJECTIVES OF THE STUDY}

The objectives of the study were:

- To identify demographic characteristics of the respondents.

- To identify challenges faced by the school administration in handling drug and substance use among students.

\section{RESEARCH METHODOLOGY}

A descriptive research design was used. Questionnaires were administered to 1002 students and 24 teachers teaching life skills. Semi structured interview schedules were used with 24 Deputy Principals, 24 Counselors and 120 Focus Group Discussions. Purposive and random sampling techniques were used to select the respondents in Nandi county schools. The study presented the results from the questionnaires in frequency tables showing frequencies and percentages on the opinions of the respondents. The study results from the interview were organized, coded and discussed based on emerging issues on drug and substance abuse.

\section{DISCUSSIONS OF STUDY FINDINGS Objective 1: Demographic characteristics of the respondents}

The researcher determined the gender, age, educational level, duration of work as well as students family background to determine the nature of the respondents.

\section{Gender}

Table-1.

The gender of the respondents is presented in

Table-1: Gender Distributions of the Respondents

\begin{tabular}{|l|l|l|l|}
\hline Students & \multicolumn{3}{|l|}{ Gender } \\
\hline & Male & Female & Total \\
\hline Frequency & 509 & 493 & 1002 \\
\hline Percent & $50.8 \%$ & $49.2 \%$ & $100 \%$ \\
\hline
\end{tabular}

Source: Field Data (2017)

Based on Table-1, the results indicated that the proportion of male students sampled was 509(50.8\%) which was higher than that of the females 493(49.2\%) among the schools.

\section{Category of Schools}

Table-2, established that boys were on the lead in all categories of mixed schools. In SCMD, boys were $500(62 \%)$ while girls were $300(38 \%)$. In CMB, boys were $233(73 \%)$ and girls were $87(27 \%)$, while, in CMD, boys were $400(63 \%)$ and girls were 240(37\%). The findings of the study were supported by research findings by [16] among students in different universities in Pakistan. The findings revealed that the percentage of drug abuse was greater in males as compared to females.

Table-2: Category of Schools

\begin{tabular}{|l|l|l|l|}
\hline & \multicolumn{2}{|l|}{ Category of Schools } \\
\hline Response & SCMD & CMB & CMD \\
\hline General distribution of DSA in mixed schools & Boys 500 (62\%) & Boys 233 (73\%) & Boys 400 (63\%) \\
& Girls 300 (38\%) & Girls 87 (27\%) & Girls 94 (31\%) \\
\hline
\end{tabular}

Source: Field Data (2017)

\section{Status of the School}

From Table-3, the findings show that the expected number of students from each class to fill and return the forms was 16 from 69 streams as clarified in table 3 giving a total of 1104 but only 1002 managed to fill and returned the forms. The return rate stood at $1002(90.7 \%)$ as shown in Table-3 as was affected in form one to form four in terms of expected and the actual count.

Table-3: Class/Form of the Respondents in Public Secondary Schools

\begin{tabular}{|l|l|l|}
\hline Class/Form & Frequency & Percentage (\%) \\
\hline One & 252 & $91.3 \%$ \\
\hline Two & 248 & $89.9 \%$ \\
\hline Three & 250 & $90.6 \%$ \\
\hline Four & 248 & $89.9 \%$ \\
\hline Total & 1002 & $90.7 \%$ \\
\hline
\end{tabular}

The objective of the study sought to examine challenges faced by teachers and learners on drug and substance abuse in public secondary schools. The study sought responses using questionnaires from students and interview schedules from Deputy Principals and Life Skills teachers and Counselors. The study responses were illustrated as follows.

\section{Objective 2: Challenges Faced by Teachers and Learners on Drug and Substance Abuse in Public Secondary Schools}

The study sought to examine the challenges faced by teachers and learners on drug and substance abuse in public secondary schools. The study results are as illustrated in Table-4. 
Table-4: Challenges Faced by the School Teachers in Handling Drug and Substance use among Students

\begin{tabular}{|c|c|c|c|c|c|c|}
\hline \multirow{3}{*}{ Responses } & \multicolumn{4}{|c|}{ D/P/LST/ C } & \multicolumn{2}{|l|}{ FGD } \\
\hline & \multicolumn{2}{|c|}{ Critical } & \multicolumn{2}{|c|}{$\begin{array}{l}\text { Less } \\
\text { Critical }\end{array}$} & \multirow{2}{*}{$\begin{array}{l}\text { Critical } \\
\text { F }\end{array}$} & \multirow{2}{*}{$\begin{array}{l}\text { Less } \\
\text { Critical } \\
\%\end{array}$} \\
\hline & $\mathbf{F}$ & $\%$ & $\mathbf{F}$ & $\%$ & & \\
\hline Identifying where students hide drugs in school & 65 & 90 & 7 & 10 & 86 & 72 \\
\hline $\begin{array}{l}\text { Collusion between students and school workers make drug } \\
\text { detection difficult }\end{array}$ & 61 & 85 & 11 & 15 & 106 & 89 \\
\hline $\begin{array}{l}\text { Improving the performance of students who have been under } \\
\text { substance abuse }\end{array}$ & 58 & 80 & 14 & 20 & 86 & 72 \\
\hline Teachers involvement in drug abuse with students & 68 & 95 & 4 & 5 & 57 & 68 \\
\hline $\begin{array}{l}\text { Joint school activities e.g. Drama, Sports, Symposiums, } \\
\text { Debates etc }\end{array}$ & 61 & 85 & 11 & 15 & 72 & 60 \\
\hline Day school students & 65 & 90 & 7 & 10 & 78 & 65 \\
\hline Students having excess pocket money & 61 & 85 & 11 & 15 & 66 & 55 \\
\hline Family challenges/Peer pressures Frustrations/ & 54 & 75 & 18 & 25 & 89 & 74 \\
\hline $\begin{array}{l}\text { Availability and accessibility of drugs within school } \\
\text { compounds/ Poor implementation of drug abuse policies }\end{array}$ & 50 & 70 & 22 & 30 & 76 & 63 \\
\hline
\end{tabular}

Key: SD=Strongly Agree, D=Disagree, U=Undecided, A=Agree, SA=Strongly Agree, \%=Percentage, F=frequency

Collusion between students and school workers make drug detection difficult was one of the challenges that were subjected for respondent's views. More than half of the respondents $61(85 \%)$ of the three major respondents combined, Deputy Principals, (DP) Life Skill Teachers (LST) and Counselors (C) and Focus Group Discussions (FGDs). 86(72\%) stated that challenges in the family were pressing and most critical limitations towards minimizing drug abuse among high schools students. Another 5\%, 10\%, and $15 \%$ of them pointed out that the challenge was least critical.

Teachers' involvement in drug abuse with students was also one of the challenges that were subjected for respondent's views. Nearly all respondents $95 \%, 90 \%, 85 \%$ of the Deputy Principals, Life Skill Teachers and Counselors respectively indicated that Teachers involvement in drug abuse with students are pressing and most critical limitations toward minimizing drug abuse among high school students. Less than half all respondents stated that the challenge of students having excess cash flow facilitate them to buying and abusing drugs was not critical. $61(85 \%)$ of the three major respondents combined, Deputy Principals, (DP) Life Skill Teachers (LST) and Counselors (C) and Focus Discussion Group (FGDs) $86(72 \%)$ of them stated it was critical. This infers that excess money among school children could be a key challenge against substance and drug abuse reduction strategies in public high schools. On ranking accessibility and availability of drugs within school compound as among the challenges impeding drug abuse reduction in public high schools, a vast majority $58(80 \%)$ of the respondents agreed that the issue was critical. This indicates that this challenge could also be a major hindrance towards reduction of drug and substance abuse among students in high schools.

When responding to joint school activities e.g. drama, sports, symposiums, and debates as to whether it could be one of the challenges. $61(85 \%)$ of the three major respondents combined, Deputy Principals, Life Skills teachers and counselors (c) and focus Discussion Group (FDGs) respectively indicated that it was among one of the most critical hindrances toward reduction of drug and substance abuse among students in public high school.

More than half $61(85 \%)$ of the three major respondents combined, Deputy principals, (DP) life skill Teachers (LST) and Teacher Counselors (TC) and Focus Group Discussions (FGDs) 86(72\%) pointed out those day school students was one of the critical challenge in drug and substance abuse reduction among students in public high school.

In connection with above challenges, it seems that the setting in which we are makes it difficult to tackle with the menace of drug abuse. Drugs are sold everywhere, even with the tight security; some drug traffickers still find their own way into schools. This was in line with Leong, Kim and Gupta [17] who exposed availability of cash to the youth as pocket money or travel allowances especially if too much can be used to purchasing of drugs .It was also supported by Adeoti and Edward [18] who concluded that peer pressure was the main factor that influenced substance abuse among campus students.

Therefore, if no interventions are put to counter peer pressure among high school students, drug abuse reduction will remain a dream to be reached. Another challenge among the study participants was the poor implementation of drug and substance abuse policies in the schools. More than half $78(65 \%)$ of all the students indicated that this challenge was critical. This infers that more than half of the students were aware that poor implementation of drug and substance abuse policies could be among the challenges hindering 
drug and substance abuse reduction among school children in public high schools.

Challenges in the family were another response that was subjected for respondent's opinions. $75(54 \%$,) of the three major respondents combined, Deputy Principals (DP) Life Skill Teachers(LST) and Counselors (C) and Focus Discussion Group (FGDs) $89(74 \%)$ stated that challenges in the family were pressing and major critical hindrances toward reduction of drug and substance abuse among secondary high school students. A few of the respondents indicated that the challenge was least critical.

More than a half $61(85 \%$,) of the three major respondents combined, Deputy Principals, (DP) Life Skill Teachers (LST) and Counselors (C) and Focus Discussion Group (FGDs) 86(72\%) reported that frustrations have made students to abuse drugs. Similarly $24 \% 20 \% 19 \%$ of them reported identifying where students hide drugs in school as the least factor that hinder drug and substance abuse reduction among students in public high school.

When responding to joint school activities e.g. Drama, Sports, Symposiums, and Debates as to whether they could be some of the challenges. $61(85 \%$,) of the three major respondents combined, Deputy Principals,(DP) Life Skill Teachers(LST) and Counselors (C) and Focus Discussion Group (FGDs) $86(72 \%)$ respectively indicated that it was among one of the most Critical hindrances toward reduction of drug abuse among students in public secondary schools.

More than half $61(85 \%$,) of the three major respondents combined, Deputy Principals, (DP) Life Skill Teachers (LST) and Counselors (C) and Focus Discussion Groups (FDGs) 86(72\%) pointed out those day school students was one of the critical challenge in drug and substance abuse reduction among students in public high school. In connection with the above challenges, it seems that the environment we are in makes it difficult to deal with the menace of drug and substance abuse.

\section{CONCLUSIONS}

There are myriad of challenges that face both teachers and students in their attempt to stop drug and substance abuse. All the reasons cited herewith were in total agreement with more than half $86 \%$ of all respondents to be the challenges hindering in menace of drug abuse among secondary school students.

- Identifying where students hide drugs in schools, collusion between students and school workers, teachers involvement in drug abuse with students. Drug abuse in schools is too secretive as is carried out in a well-coordinated manner right from outside the schools and within the schools.

- All the respondents-Deputy Principals, Guidance and Counseling and Life Skills teachers were in agreement that they were facing challenges in their attempt to tame DSA in their schools. Factors they pinpointed as contributing to these challenges were problem in identifying where students hide drugs in school.

- Collusion between students and school workers make drug detection difficult, improving the performance of students who have been under substance abuse, teacher's involvement in drug abuse with students, joint school activities for example, drama, sports, symposiums and debates.

- Day school students who have free times to engage in the vice, Students having excess pocket money, Family challenges, Per pressures, Frustrations, Availability and accessibility of drugs within school compounds and Poor implementation of drug abuse policies.

\section{RECOMMENDATIONS}

- Guidance and counseling in schools should be revamped, intensified and adequately resourced to cater for the needs of all students including those affected by drugs.

- All stake-holders including referral agencies and the wider community should work together to make decisions on drug use policy, together with the management of drug incidents.

\section{REFERENCES}

1. Gilbert, J. B., Kenneth, W. G., \& Leigh, Z. G. (2001). Drug and alcohol Abuse. School, College. Stare University. Retrieved from https:/education.stateuniversity.com/pages/1923/ Drug-Alcohol-Abuse.html.

2. Beschner, G. M., \& Friedman, A. S. (1979). Youth drug abuse, problems, issues and treatment. Lexington Books DC. Heath \& Company: Toronto.

3. Edmonds, L., \& Wilcocks, L. (2000). Teen drug scene: a guide for parents and schools. Wendywood: Little Oak Press.

4. Levant, M. (1995). Substance Abuse in young people- Wiley Online library

5. Adelekan, M. (1999). Rapid Situation Assessment of the Drug Situation at Ehin - Etiri, Ijebu North Local Government, Ogun State Nigeria. Lagosi: UNDCP. African Journal of Drug \& Alcohol studies.

6. NACADA. (2002). Youth in peril, (alcohol and drug abuse) in Kenya. Nairobi: Government Printer.

7. Daily Nation Newspaper. (2003). School workers and students collaborating in infiltrating drugs into schools.

8. Gillis, H. (1996). Counseling Young People. Sigma Press, Koendoe Poort. Pretoria

9. The Nigerian National Drug Law Enforcement Agency. (2015). Drug Abuse a real monster in schools. 
10. Hawkins, J. D., Catalano, R. F., \& Miller, J. M. (2002). Risk and protective factors for alcohol and other drug problems in adolescence and early childhood: Implications for substance abuse prevention. Psychological Bulletin, 12, 64-105.

11. Gathumbi, A. M. (2003). Family and peer influences on substance abuse among Secondary school students in Thika District. Unpublished PGDE Project, Catholic University of eastern Africa.

12. Global Tobacco Youth Survey-Kenya (2006). Smoking prevalence and tobacco control measures in Kenya, Uganda, The Gambia and Liberia: A Review.

13. Rapid Assessment on Drug and Substance. (2012). Drug and substance abuse in Kenya has reached an agonizing stage.

14. Leong, K., \& Gupta. (2011). Peer Substance use associated co-occurrence of borderline personality disorder features and drug use problems in college students. Journal of American College of Health, 59(5), 678-897.

15. US Department of Education. (1986). The Educational Systems in the United States

16. Zarman, A. (2015). Drug Abuse among the Students Junaid Qureshi-Academia. Edu. https://doi.org/10.22200/pjpr.2015141-47.

17. Adeoti, F., \& Edward, S. (2010). Factors influencing substance abuse among undergraduate students in Osun State, Nigeria. An International Multi-disciplinary Journal, 4(4), 330-340.

18. Leong, F. T., Kim, H. H., \& Gupta, A. (2011). Attitudes toward professional counseling among Asian-American college students: Acculturation, conceptions of mental illness, and loss of face. Asian American Journal of Psychology, 2(2), 140. 